Animal Health Research Institute, Ismailia

\title{
ASCITES SYNDROME IN BROILERS WITH SPECIAL REFERENCE TO EXISTENCE OF BACTERIAL ETIOLOGY AND STUDY THEIR PATHOLOGICAL ALTERATIONS
}

(With 7 Tables and 16 Figures)

By

\section{M.K.MOURSI and SOHAIR Y. MOHAMED}

(Received at 22/1/2008)

الاستسقاء في بداري التسمين بالإشارة إلى وجود المسببات البكتيرية ودراسة

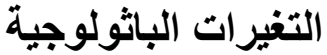

\section{محد كمال مرسي دسوقي ، سهير بيوسف محمد}

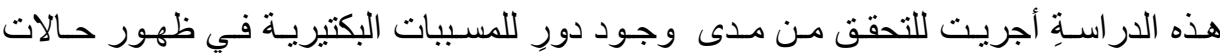

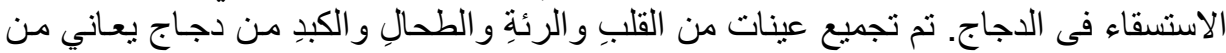

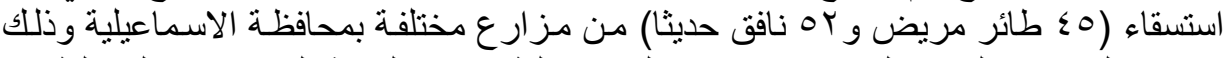
لإجراء الفحوص البكتريولوجيه وتم اجراء الفحص الظاهرى و الصفة التشريحيه على الطى الطيور

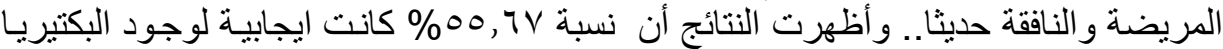

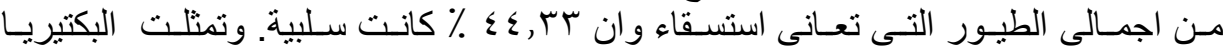

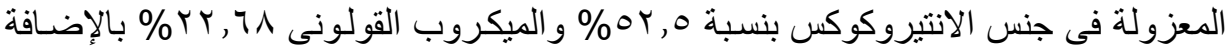

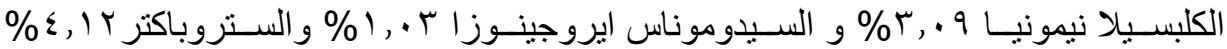

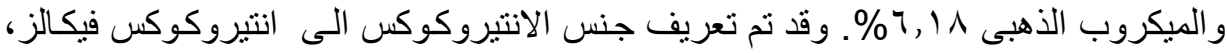
انتيروكوكس ديور انس، انتيروكوكس هايرى. وقد تبين ان ميكروبـات الانتيروكوكس حس حساسـة

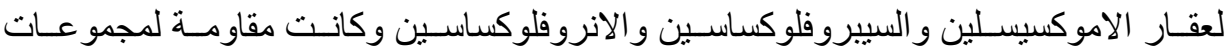

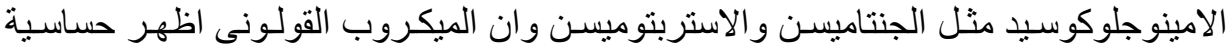

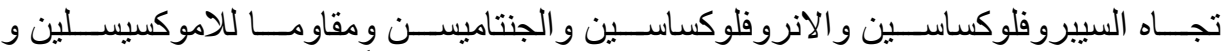

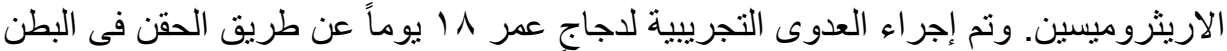

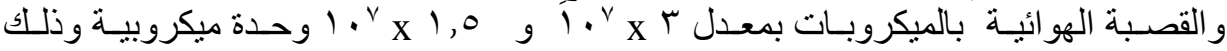

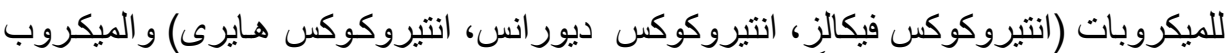

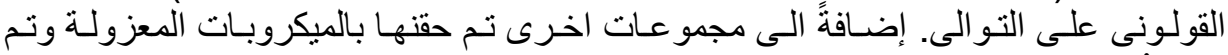

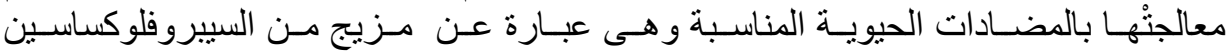

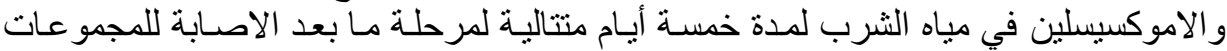

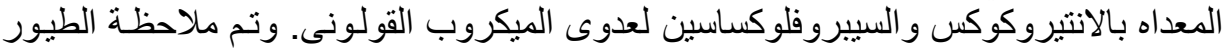

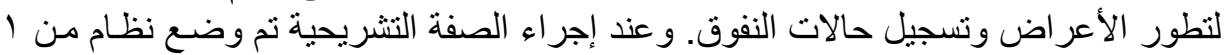

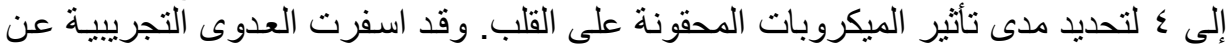

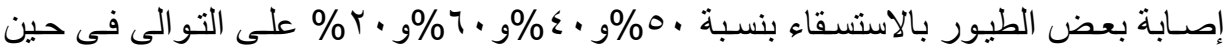




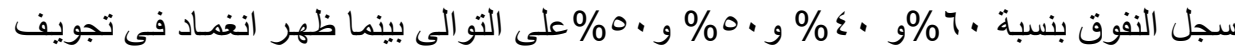

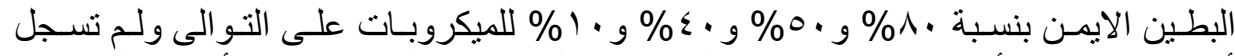

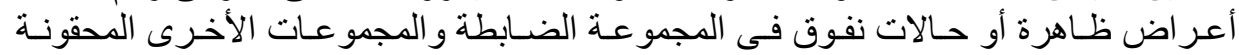

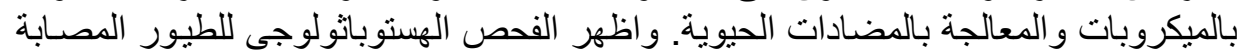

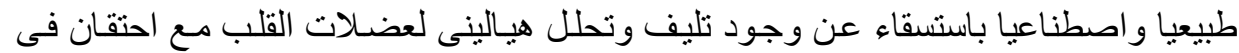

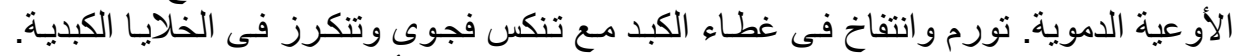

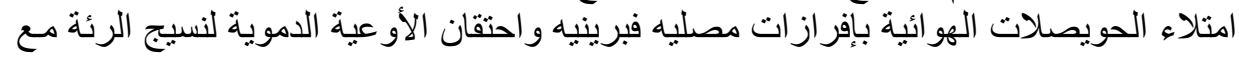

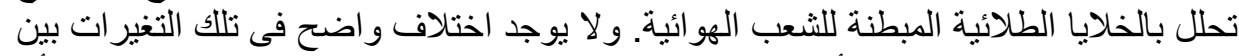

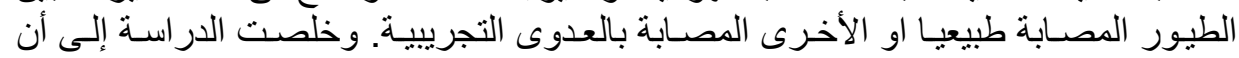

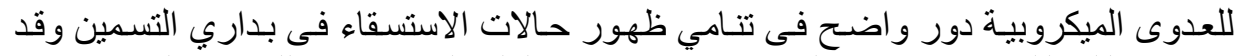

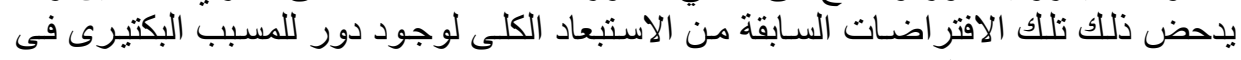
ظهور الاستسقاء فى الدجاج.

\section{SUMMARY}

This study was performed to investigate the existence of bacterial etiology in development of ascites in broiler chickens. Samples of heart, lung, spleen and liver were collected from broiler chickens suffered from ascites (45 diseased and 52 freshly dead) for bacteriological and histopathological examinations from different farms at Ismailia province. The results showed that the overall incidence of bacterial isolation from ascitic birds were (55.67\%) while, (44.33\%) was negative for bacterial isolation. The most frequently isolated bacteria were Enterococcus spp. (52.5\%), and E. coli (22.68\%) besides Klebsiella pneumoniae $3.09 \%$, Pseudomonas aeruginosa 1.09\%, Citrobacter 4.12\%. and Staphylococcus (6.18\%). Enterococcus spp. was identified as Enterococcus faecalis, Enterococcus durans, Enterococcus hirae. Escherichia coli isolates were found serologically to be belong to 078, 0111 and untypable. Isolated Enterococcus spp. were highly sensitive to amoxicillin and sensitive to ciprofloxacin and enrofloxacin while they were resistant to Aminoglycoside (gentamycin and streptomycin), tetracycline and Chloramphenicol. Isolated E. coli was resistance to amoxicillin and erythromycin and sensitive to ciprofloxacin, enrofloxacin and gentamycin. Experimental infection of 18 day-old chickens inoculated intraabdominal and intratracheal with approximately $3 \times 10^{7} \mathrm{CFU}$ and $1.5 \times 10^{7}$ (Enterococcus faecalis, Enterococcus durans, Enterococcus hirae) and E. coli respectively in addition to, another same inoculated groups and treated with susceptible antibiotics as combination of Ciprofloxacin and Amoxicillin in drinking water for five successive days post infection for enterococus spp groups and 
ciprofloxacin alone for E. coli infected group. Birds were monitored daily for clinical signs and mortalities .At necropsy a subjective scoring system was devised to quantify challenge effect by assigning each heart score of 1 to 4 . the average of birds exhibiting ascites were $60 \%, 40 \%, 50 \%$ and $20 \%$ while mortalities were $60 \%, 40 \%, 50 \%$ and $50 \%$ as well as birds developing ventricular cavity were $80 \%, 50 \%, 40 \%$ and $10 \%$ for Enterococcus faecalis, Enterococcus durans, Enterococcus hirae) and E. coli infected groups respectively. All infected and treated birds developed neither clinical signs nor mortalities. No clinical signs or gross lesions were demonstrated in control birds. Histopathological examination revealed epicardial fibrosis, hyaline degeneration of myocardial muscles, thickening of the fibrous tissue of the hepatic capsule, vacuolar degeneration and necrosis. The Lung showing serofibrinous exudates inside the alveoli and congestion of the blood vessels, desquamation of the epithelial cells of the bronchioles. No great differences was found in histopathological finding between naturally and experimentally infected birds It could be concluded that bacterial agents have a considerable role in development of ascites in broiler chickens. It clearly refutes the postulation of complete exclusion of infectious agents as an etiology of ascites development in broilers

Key words: Broilers, ascites,Enterococcei, antibiotic sensitivity

\section{INTRODUCTION}

Over the past 30 years, cardiopulmonary diseases have become an escalating concern for the commercial broiler industry. Ascites is a major cardiopulmonary condition in young chickens that causes economic losses by increase the incidence of mortality due to premature death, as well as carcass condemnation at processing (Tankson et al., 2002c) and (Druryan et al., 2007).

This condition was first recognized in fast-growing chickens reared at high altitudes, i.e., above 3,500 m (Julian, 1998), afterward it was reported in both normal and high attitudes. It has been termed heart failure syndrome," "water belly," and "pulmonary hypertension syndrome" (PHS) (Tankson, 2001). It is characterized by an excessive amount of serous fluid (amber or clear plasma-like fluid) accumulated in the pericardial sac, hepatic tree, and/or peritoneal cavity (Tafi and Karima 2000).

The average incidence of ascites in broiler flocks worldwide is 4.7\% (Maxwell and Robertson 1997). 
Ascites secondary to right ventricular failure (RVF) occurs worldwide in growing broiler chickens and is a significant cause of mortality in many flocks (Saif et al., 2003). Pulmonary hypertension syndrome is caused by insufficient oxygen saturation in the blood. The heart compensates by increasing contractility of the right ventricle to deliver more blood to the pulmonary tree. Thus, pulmonary hypertension occur. Over time, the right ventricular wall hypertrophies, then dilates. This leads to right ventricular failure, accumulation of ascitic fluid in serous cavities and finally death (Julian, 1993).

Mortality due to ascites syndrome can range up to $5 \%$ in broiler flocks and up to $20 \%$ in heavier roaster flocks (Janice, 2003).

Research indicates that there are many physiological and pathological explanations as to why PHS occurs. These reasons include environmental, nutritional, chemical, genetic, strain type, and management of the broiler. Even though these are well-founded explanations, one explanation that has not been evaluated is bacteria.

Microbial pathogens have not been implicated as a cause of ascites in any animal. Until, Tankson et al. (2001) reported that heart and lungs of broilers do not have a permanent bacterial flora; however, different bacteria were found in these organs. Thus, he found some of these bacteria seemed to be a logical choice to investigate as a putative causative agent of ascites in broilers. Enterococcus faecalis (E. faecalis) has been recently added to the list of agents and conditions that cause PHS. It is part of the normal flora of the intestinal tract in humans and chickens (Tankson et al., 2002 c). Yamaguchi et al. (2000) induced ascites experimentally in broiler chickens using Escherichia coli. In spite of this, many researches exclude generally infectious agent as a possible cause of ascites. Therefore, the objective of this study was to determine if bacteria can cause PHS and consequently ascites developed in broiler chickens by:-

- Isolation and identification of bacteria existed in the heart and lungs of ascitic broilers.

- challenging the broiler chickens with more frequently isolated bacteria to determine if signs of ascites develop.

- As well as determining their patterns of antimicrobial resistance.

- Investigation of pathological alteration in different organs in the affected birds.

\section{MATERIALS and METHODS}




\section{Birds and samples:}

A total no of 97 birds suffered from ascites (45 diseased and 52 freshly dead) were collected from different farms at Ismailia province. Complete clinical signs and postmortem examination were carried out on diseased and dead birds respectively. Samples of heart, lung, spleen and liver were collected for bacteriological examination as well as histopathological examination.

\section{Bacteriological examination:}

Samples of heart, lung, spleen and liver as well as pericardial fluids were inoculated into nutrient broth, brain heart infusion broth and incubated at $37{ }^{\circ} \mathrm{C}$ aerobically for 24-48 hrs. Streaked over blood agar, brain heart infusion agar, MacConkey agar and incubated for 24-48 hrs at $37^{\circ} \mathrm{C}$ aerobically.

Suspected colonies were subjected for further identification using colonial and cellular morphology as well as biochemical tests Quinen et al. (1994 and 2002).

E.coli isolates were serotyped according to Edwards and Ewing (1972).

\section{Identification of Enterococcus spp.}

After presumptive diagnosis of suspected Enterococcus spp. based on gram stain and colony morphology, suspected colonies of pure cultures (Gram-positive cocci, catalase negative) were investigated for identification of Enterococcus isolates by Serogrouping for groups (A, B, C, D, F and G) using streptococcal grouping kit (Oxoid DR $585 \mathrm{~A})$. Also tolerance to growth in $6.5 \%$ salt, bile esculin hydrolysis, fermentation of pyruvate, motility, pigment production, haemolysis in sheep blood agar, carbohydrates fermentation (mannitol, sorbitol, arabinose and lactose) was also accomplished according to (Linda and Paul, 1992).

\section{Antibiogram study:}

Antimicrobial susceptibility pattern of the isolated bacteria were determined by disc diffusion methods on Muller Hinton agar according to NCCLS (2002) using different chemotherapeutic agents.

\section{Histopathology:}

Tissues specimens from heart, lungs, liver and spleen were taken from freshly dead and sacrificed chicks, fixed in $10 \%$ buffered neutral formalin solution, then, paraffin sections of 5 microns thickness were prepared and stained with Hemotoxylin and Eosin according to Bancroft et al. (1990).

\section{Pathogenicity:}




\section{Experimental infection design:}

Ninety-(one-day old) broiler chickens of a common commercial strain of both sex were obtained. Birds were reared on clean separate pen with food and water available ad libitium. At 18 day of age, birds were divided into two main groups A and B. Group (A) was divided into five subgroups, 10 birds each and used in pathogenicity study while group (B) was divided into 4 subgroups, 10 birds each and used for study the effect of susceptible antibiotic on inoculated bacteria according to the following scheme:

\section{I - pathogencity test: (Group A):}

Subgroup 1: chickens were inoculated with $0.5 \mathrm{ml}$ of broth culture containing $3 \times 10^{7} \mathrm{CFU}$ of E. faecalis intraabdominally according to Tankson ,(2001) and Tankson et al. (2001)

Subgroup 2: chickens were inoculated with $0.5 \mathrm{ml}$ of broth culture containing $3 \times 10^{7} \mathrm{CFU}$ of $E$. durans intraabdominally.

Subgroup 3: chickens were inoculated with $0.5 \mathrm{ml}$ of broth culture containing $3 \times 10^{7} \mathrm{CFU}$ of E. hirae intraabdominally.

Subgroup 4: chickens were inoculated with $0.3 \mathrm{ml}$ of broth culture containing $1.5 \times 10^{7} \mathrm{CFU}$ of Escherichia coli (078) intratracheally according to Yamaguchi et al. (2000)

Group 5: kept as Control.

\section{II - treatment trial: (Group B):}

All inoculated birds received susceptible antibiotics $24 \mathrm{hrs}$ post infection.

Subgroup 1: chickens were inoculated with $0.5 \mathrm{ml}$ of broth culture containing $3 \times 10^{7} \mathrm{CFU}$ of E. faecalis intraabdominally and treated with combination of ciprofloxacin and amoxicillin in drinking water for five successive days post infection.

Subgroup 2: chickens were inoculated with $0.5 \mathrm{ml}$ of broth culture containing $3 \times 10^{7} \mathrm{CFU}$ of $E$. durans intraabdominally and treated with combination of ciprofloxacin and amoxicillin in drinking water for five successive days post infection

Subgroup 3: chickens were inoculated with $0.5 \mathrm{ml}$ of broth culture containing $3 \times 10^{7} \mathrm{CFU}$ of E. hirae intraabdominally and treated with combination of ciprofloxacin and amoxicillin in drinking water for five successive days post infection.

Subgroup 4: chickens were inoculated with $0.3 \mathrm{ml}$ of broth culture containing $1.5 \times 10^{7} \mathrm{CFU}$ of Escherichia coli (078) intratracheally and treated with ciprofloxacin alone in drinking water for five successive days post infection. 
Chicken were monitored daily for clinical signs of fatigue, increase respiratory rate and ascites. All birds showing clinical signs were marked. At the end of the experiment, birds were sacrificed and detailed postmortem examinations were carried out. A subjective scoring system was devised to quantify challenge effects by assigning each heart score of 1 to 4 according to (Tankson et al. 2002 b). A score of 1 was given if the heart appeared normal and possessed normal muscular tone. A score of two was assigned if a cavity or depression was visible on the exterior surface of the RVW and if the heart possessed normal muscular tone. A score of three was assigned if the RVW exhibited the cavity and the heart was slightly flaccid. Finally, a score of four was assigned if the cavity was present and the heart was very flaccid.

\section{RESULTS}

\section{Clinical signs:}

Clinically affected broilers are smaller than normal and listless with ruffled feathers, pale shrunken comb, reluctant to move, and were dyspneic, increase respiratory rate and cyanotic. Severely affected birds had abdominal distension (Fig.1). Some birds died suddenly before ascites develop.

\section{Post mortem lesion:}

The postmortem lesions were severe marked venous congestion with deep red colour of the carcasses musculature (Fig.2). Accumulation of straw yellow to tinged with blood fluid in the pericardial sac and /or abdominal cavity were seen. The liver of the affected birds varied from swollen and congested, or firm and irregular with edema and had fibrin adherent to the surface. Lungs are congested and edematous. The heart showed cardiac enlargement includes dilation of the right atrium, and vena cava as well as the right ventricle and hypertrophy of both the right ventricle and right muscular atrioventricular valve. Nodular thickening of the atrioventricular valves is characteristic of hearts from ascitic birds. Hydro pericardium was also present.

\section{Bacteriological examination:}

The results of bacteriological examination revealed that the overall incidence of bacterial isolation from ascitic birds were $55.67 \%$ while $44.33 \%$ was negative for bacterial isolation (Table 2). Enterococcus spp. E. coli, Klebsiella pneumoniae, Pseudomonas aeruginosa, Cirobacter and Staphylococcus are the most common isolated bacteria with variable percentages from diseased and freshly dead ascitic birds as shown in Table (1). High prevalence of 
Enterococcus spp. were isolated 23/45 (51.11)\%, and 28/52 53.84\% respectively from diseased and dead birds. Escherichia coli isolates were found serologically to belong to 078,0111 and untypable serotypes.

\section{Identification of Enterococcus spp.}

Pure culture of Enterococcus spp. appeared as grey transparent to white colonies $0.5-1 \mathrm{ml}$ in diameter. They were gram positive cocci observed single, pairs or short chain, reacting with group D of serological scheme of Lancfield, Catalase negative, non motile, grow on MacConkey agar and BHI agar supplemented with $6.5 \% \mathrm{NaCl}$.

Table (3) showed that Enterococcus species were identified as Enterococcus faecalis, Enterococcus durans, Enterococcus hirae. Enterococcus faecalis was isolated in more chicken and at more time than any other bacteria 35/51 (68.63\%) followed by Enterococcus durans 10/51(19.6 \%), Enterococcus hirae 6/51 (11.76\%) as shown in table (4). Table (5) showed the results of antimicrobial sensitivity patterns of Enterococcus spp. isolated from ascitic birds.

\section{Experimental study:}

Clinical signs, P.M and mortality rate of experimentally infected chickens was summarized in table (6). Clinically, the inoculated nontreated birds showed increased respiratory rate, reduce exercise tolerance and ruffling of feather from 4 - 7 days post infection. Some birds showed distended abdomen with pale head 11 days post infection.

At necropsy the demonstrated lesions interpreted as picture of septicemia including general hyperemia, dark liver with hepatomegaly , spleenomegaly (Fig. 4). Perihepatitis and pericarditis were also observed. Some birds showed straw yellow fluid occupying the abdominal cavity Fig. (3). Liver was congested and some birds developed hydropericardium (Fig. 5). No birds were found to be suffering from both ascites and pericarditis especially in E.coli infected group. Hearts were severely enlarged showing visible cavity in the external right ventricular wall (RVW) (Fig. 7 and 8). The average incidence of cavity occurrence were 80, 50, 40 and 10 in groups 1, 2, 3 and 4 respectively. Additionally the average incidence of cavity formation for Enterococci spp. was (17/30) $56.66 \%$. Other hearts showed typical postmortem cardiac enlargement associated with ascites as left and right ventricular dilation.

Mortality rate were $60 \%, 40 \%, 50 \%$ and $50 \%$ for Enterococcus faecalis, Enterococcus durans, Enteococcus hirae and E. coli respectively. Control group did not develop any clinical signs and mortalities were not recorded. 
Neither clinical signs nor mortalities were recorded in all infected and treated groups. Table (7) shows the incidence of bacterial recovery from inoculated birds at the end of the experiment.

\section{The results of histopathological examinations:}

\section{A- Natural ascites syndrome:}

Heart showed epicardial fibrosis due to proliferation of collagen fiber and fibrocytes (Fig. 9)., in addition to hyaline degeneration and destruction of cardiac muscle fiber with leucocytic infiltration and edema among the cardiac muscle fiber (Fig. 10). Lung revealed serofibrinous pneumonia. congestion of the pulmonary blood vessels. The alveoli were filled with serofibrinous exudates containing mononuclear cells mainly lymphocytes and macrophage, in addition to collapse and compensatory emphysema The bronchi and bronchioles showed hyperplasia and desquamation of their epithelial cells with perbronchial mononuclear cells infiltration (Fig. 11). Liver: showed vacuolar degeneration and necrosis of the hepatic cells together with severe congestion and dilation of the hepatic sinusoid and central veins ,thickening and hyalinization of the fibrous tissue of the hepatic capsule could be seen (Fig. 12). Spleen showed congestion of the splenic blood vessels with thickening in their walls. Splenic tissues revealed necrosis and depilation of hypatocytes of the white bulb (Fig. 13) the splenic capsule is thickened and covered by fibrin mononuclear cells.

B- Experimentally infected chicks: Showed similar signs and lesions to the naturally infected chicks. No great difference was observed between the different groups. Heart: revealed hyaline degeneration and necrosis of the cardiac muscle fiber with edema. The destructed cardiac muscle were replaced by fibroblast and mononuclear cells (Fig. 14). The pericardium and epicardium were thickened by dilated congested blood vessels and proliferation of fibers and fibroblast. Lung: showed congestion of the blood vessels with perivascular edema and hyperplasia of the endothelial cells lining the blood vessels with thickening and hyalinization of their wall. The alveoli contained fibrinous exudates mixed with mononuclear cells .also the pulmonary tissue showed thickening in the interlobular septa by dilated congested blood vessels and fibrinous fluids (Fig. 15). Spleen showed congestion and dilation of the splenic blood vessels with hyperplasia of the endothelial lining Bl.Vs. Splenic tissues revealed necrosis and depletion of lymphocytes of the white bulb. Thickening of the splenic capsule was observed. Liver showed thickening of the fibrous tissue of the hepatic capsule. Proliferation of the fibrous tissue, edema and leucocytic infilteration 
were observed in the portal area, in addition to congestion and dilation of the hepatic sinusoid and central vein. The hepatic cells showed vacuolar degeneration and necrosis (Fig.16).

Table 1: Bacteria isolated from ascitic chicks

\begin{tabular}{|l|c|c|c|c|}
\hline \multirow{2}{*}{ Isolated bacteria } & \multicolumn{2}{|c|}{ Diseased birds } & \multicolumn{2}{c|}{$\begin{array}{c}\text { Dead birds } \\
\mathrm{N}=52\end{array}$} \\
\cline { 2 - 5 } & No. & $\%$ & No. & $\%$ \\
\hline Enterococcus spp. & 23 & 51.11 & 28 & 53.84 \\
\hline Escherichia coli & 10 & 22.22 & 12 & 23.07 \\
\hline Klebseilla pneumoniae. & 1 & 2.22 & 2 & 3.84 \\
\hline Pseudomonas aeruginosa & 1 & 2.22 & - & 0.0 \\
\hline Staphylococcus spp. & 3 & 6.66 & 3 & 5.76 \\
\hline Citrobacter spp. & 2 & 4.44 & 2 & 3.84 \\
\hline
\end{tabular}

$\mathrm{N}=$ no. of examined birds.

N.B mixed infection was encountered and more than one microbe was isolated from the same sample simultaneously.

Table 2: incidence of positive and negative broilers for bacterial isolation.

\begin{tabular}{|c|c|c|c|c|c|c|c|c|c|c|c|}
\hline \multicolumn{3}{|c|}{$\begin{array}{c}\text { Diseased birds } \\
\text { N=45 }\end{array}$} & \multicolumn{3}{c|}{$\begin{array}{c}\text { Dead birds } \\
\mathrm{N}=52\end{array}$} & \multicolumn{4}{c|}{$\begin{array}{c}\text { total incidence } \\
\text { N = 97 }\end{array}$} \\
\hline \multicolumn{2}{|c|}{ Positive } & Negative & \multicolumn{2}{c|}{ Positive } & Negative & \multicolumn{2}{c|}{ Positive } & \multicolumn{2}{c|}{ Negative } \\
\hline No. & $\%$ & No. & $\%$ & No. & $\%$ & No. & $\%$ & No. & $\%$ & No. & $\%$ \\
\hline 24 & 53.33 & 21 & 46.67 & 30 & 57.69 & 22 & 42.31 & 54 & 55.67 & 43 & 44.33 \\
\hline
\end{tabular}

Table 3: Results of identification and some characteristics of the isolated Enterococcus spp.

\begin{tabular}{|c|c|c|c|c|c|c|c|c|c|c|c|}
\hline \multirow{3}{*}{$\begin{array}{c}\text { Enterococcus } \\
\text { species }\end{array}$} & \multicolumn{11}{|c|}{ Test result } \\
\hline & \multirow{2}{*}{ 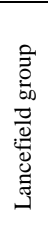 } & \multirow[b]{2}{*}{$\begin{array}{l}\stackrel{\gtrsim}{\Xi} \\
\stackrel{0}{0}\end{array}$} & \multirow[b]{2}{*}{ 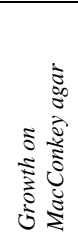 } & \multirow[b]{2}{*}{ 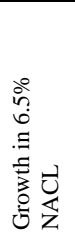 } & \multicolumn{7}{|c|}{ Carbohydrates fermentation } \\
\hline & & & & & $\begin{array}{l}\mathscr{0} \\
\stackrel{0}{0} \\
\tilde{J} \\
\end{array}$ & $\begin{array}{l}\overline{\stackrel{\vartheta}{\Xi}} \\
\text { 䒕 }\end{array}$ & 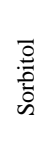 & $\begin{array}{l}0 \\
\mathscr{0} \\
: \\
: \\
\ddot{n}\end{array}$ & 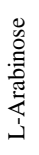 & 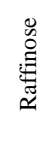 & 皇 \\
\hline $\begin{array}{l}\text { Enterococcus } \\
\text { faecalis }\end{array}$ & $\mathrm{D}$ & - & + & + & + & + & + & + & - & - & - \\
\hline $\begin{array}{l}\text { Enterococcus } \\
\text { durans }\end{array}$ & $\mathrm{D}$ & - & + & + & + & + & - & - & - & - & - \\
\hline $\begin{array}{l}\text { Enterococcus } \\
\text { hirae }\end{array}$ & $\mathrm{D}$ & - & + & + & + & - & - & + & - & + & - \\
\hline
\end{tabular}

Table 4: The incidence of isolated and identified Enterococcus spp. From diseased and dead birds.

\begin{tabular}{|l|c|c|c|c|l|}
\hline \multirow{2}{*}{ Enterococcus spp. } & \multicolumn{2}{|c|}{ Diseased birds } & \multicolumn{2}{c|}{ Dead birds } & \multirow{2}{*}{$\begin{array}{l}\text { Total no. of } \\
\text { isolates }\end{array}$} \\
\cline { 2 - 6 } & No. & $\%$ & No. & $\%$ & isole \\
\hline
\end{tabular}


Assiut Vet. Med. J. Vol. 54 No. 117 April 2008

\begin{tabular}{|l|c|c|c|c|c|}
\hline Enterococcus faecalis & 14 & 60.86 & 21 & 75 & 35 \\
\hline Enterococcus durans & 5 & 21.73 & 5 & 17.85 & 10 \\
\hline Enterococcus hirae & 4 & 17.39 & 2 & 7.14 & 6 \\
\hline
\end{tabular}

$\mathrm{N}=$ no. of isolated enterococcus spp.

Table 5: Number and frequency of antimicrobial sensitivity patterns of Enterococcus spp. Isolated from ascitic birds

\begin{tabular}{|l|c|c|c|c|}
\hline & $\begin{array}{c}\text { Enterococcus } \\
\text { faecalis } \\
\mathrm{N}_{1} / \mathrm{N}_{2}(\%)\end{array}$ & $\begin{array}{c}\text { Enterococcus } \\
\text { durans } \\
\mathrm{N}_{1} / \mathrm{N}_{2}(\%)\end{array}$ & $\begin{array}{c}\text { Enterococcus } \\
\text { hirae } \\
\mathrm{N}_{1} / \mathrm{N}_{2}(\%)\end{array}$ & $\begin{array}{c}\text { Escherichia } \\
\text { coli }\end{array}$ \\
\hline Amoxicillin $(\mathrm{AM}-10 \mu \mathrm{g})$ & $34 / 35(97.14)$ & $9 / 10(90)$ & $5 / 6(83.33)$ & $0 / 22(0.0)$ \\
\hline Chloramephenicol $(\mathrm{C}-10 \mu \mathrm{g})$ & $17 / 35(48.57)$ & $3 / 10(30)$ & $2 / 6(33.33)$ & $12 / 22(54.54)$ \\
\hline Enrofloxacin $(\mathrm{Enr}-10 \mu \mathrm{g})$ & $28 / 35(80)$ & $7 / 10(70)$ & $4 / 6(66.66)$ & $20 / 22(90.90)$ \\
\hline Ciprofloxacin $(\mathrm{Cip}-5 \mu \mathrm{g})$ & $27 / 35(77.14)$ & $8 / 10(80)$ & $5 / 6(83.33)$ & $19 / 22(86.35)$ \\
\hline Gentamycin $(\mathrm{Gn}-10 \mu \mathrm{g})$ & $13 / 35(37.14)$ & $4 / 10(40)$ & $3 / 6(50)$ & $19 / 22(86.35)$ \\
\hline Erythromycin $(\mathrm{E}-15 \mu \mathrm{g})$ & $18 / 35(51.42)$ & $5 / 10(50)$ & $3 / 6(50)$ & $0 / 22(0.0 \%)$ \\
\hline Streptomycin $(\mathrm{S}-10 \mu \mathrm{g})$ & $14 / 35(40)$ & $4 / 10(40)$ & $3 / 6(50)$ & $14 / 22(63.63)$ \\
\hline Tetracycline & $10 / 35(28.57)$ & $2 / 10(20)$ & $1 / 6(16.66)$ & $12 / 22(54.54)$ \\
\hline
\end{tabular}

$\mathrm{N}_{1}=$ Number of sensitive isolates.

$\mathrm{N}_{2}=$ Total number of isolates.

Table 6: The results of clinical signs, postmortem and mortality percentage of experimentally inoculated birds

\begin{tabular}{|l|c|c|c|c|c|c|c|c|c|}
\hline \multirow{2}{*}{ Inoculated bacteria } & \multicolumn{2}{|c|}{ Ascites } & \multicolumn{2}{|c|}{ Pericarditis } & $\begin{array}{c}\text { Enlarged } \\
\text { right or left } \\
\text { ventricle and } \\
\text { cavity } \\
\text { formation in } \\
\text { RVW }\end{array}$ & Grossly normal & \multirow{2}{*}{ Mortality \% } \\
\cline { 2 - 11 } & No. & $\%$ & No. & $\%$ & No. & $\%$ & No. & $\%$ & \\
\hline Enterococcus faecalis & $6 / 10$ & 60 & $2 / 10$ & 20 & $8 / 10$ & 80 & $0 / 10$ & 0.0 & 60 \\
\hline Enterococcus durans & $4 / 10$ & 40 & $1 / 10$ & 10 & $5 / 10$ & 50 & $1 / 10$ & 10 & 40 \\
\hline Enterococcus hirae & $5 / 10$ & 50 & $0 / 10$ & 0.0 & $4 / 10$ & 40 & $1 / 10$ & 10 & 50 \\
\hline Escherichia coli & $2 / 10$ & 20 & $4 / 10$ & 40 & $1 / 10$ & 10 & $3 / 10$ & 30 & 50 \\
\hline Control & - & - & - & - & - & - & $10 / 10$ & 100 & 0.0 \\
\hline
\end{tabular}

RVW = Right Ventricular Wall.

Table 7: Recovery of bacteria from experimentally inoculated chicks

\begin{tabular}{|c|c|c|c|c|c|c|}
\hline Organs & $\begin{array}{c}\text { Escherichia } \\
\text { coli }\end{array}$ & $\begin{array}{c}\text { Enterococcus } \\
\text { faecalis }\end{array}$ & $\begin{array}{c}\text { Enterococcus } \\
\text { durans }\end{array}$ & $\begin{array}{c}\text { Enterococcus } \\
\text { hirae }\end{array}$ & \multicolumn{2}{|c|}{ Total } \\
& & & & & No. & $\%$ \\
\hline & $\mathrm{N}_{1} / \mathrm{N}_{2}(\%)$ & $\mathrm{N}_{1} / \mathrm{N}_{2}(\%)$ & $\mathrm{N}_{1} / \mathrm{N}_{2}(\%)$ & $\mathrm{N}_{1} / \mathrm{N}_{2}(\%)$ & & \\
\hline
\end{tabular}


Assiut Vet. Med. J. Vol. 54 No. 117 April 2008

\begin{tabular}{|c|c|c|c|c|c|c|}
\hline Heart & $6 / 10(60)$ & $10 / 10(100)$ & $7 / 10(70)$ & $8 / 10(80)$ & 31 & 77.5 \\
\hline Lung & $7 / 10(70)$ & $8 / 10(80)$ & $5 / 10(50)$ & $4 / 10(40)$ & 24 & 60 \\
\hline Spleen & $7 / 10(70)$ & $7 / 10(70)$ & $3 / 10(30)$ & $4 / 10(40)$ & 21 & 52.5 \\
\hline Liver & $5 / 10(50)$ & $4 / 10(40)$ & $2 / 10(20)$ & $4 / 10(40)$ & 15 & 37.5 \\
\hline
\end{tabular}

$\mathrm{N}_{1}=$ Number of samples that possessed bacteria.

$\mathrm{N}_{2}=$ Total number of samples. 
Assiut Vet. Med. J. Vol. 54 No. 117 April 2008

$r \leq 7$ 


\section{LIST OF FIGURES}

Fig. 1: Naturally infected birds showed ruffling of feather, reluctant to move and distended abdomen

Fig. 2: Naturally infected birds marked venous congestion thought the carcasses with deep red colour of musculature.

Fig. 3: Experimentally infected chicks with straw yellow fluid occupying the abdominal cavity.

Fig. 4: Experimentally infected chicks showed dark hepatomegaly, spleenomegaly and markedly enlargement right and left ventricles of the heart

Fig. 5: hydropericardium of experimentally infected birds.

Fig. 6: Enlarged heart (right) compared with a normal heart (left) of experimentally affected chicks.

Fig. 7: Cross section through the enlarged heart at free edge level showing thinning, dilation and hypertrophy of the right ventricle compared with a transverse section through the normal heart 
Fig. 8: Hearts from experimentally infected chickens' illustrating the scoring system. Heart with normal appearance score of 1 . (Left). Cavity in the external surface of RVW (right ventricular wall) score of 2. (Middle).Flaccid heart in the right score 3.

Fig. 9: Heart of naturally infected chicks with ascites showing epicardial fibrosis, hyaline degeneration, destruction of cardiac M.F with edema and leucocytic infilteration. H\&E. X 100

Fig. 10: Heart showing edema among degenerated cardiac M.F with leucocytic infiltration. H\&E. X 100

Fig. 11: Lung of naturally infected chicks showing serofibrinous exudates inside the alveoli and congestion of the blood vessels in addition to collapse and compensatory emphysema. H\&E. X 100

Fig. 12: Liver naturally infected chicks showing thickening and hyalinization of the fibrous tissue of the hepatic capsule. H\&E. X 100

Fig. 13: Spleen naturally infected chicks showing necrosis and depletion of lymphocytes of the white bulp and congestion of splenic blood vessels. H\&E. X 100

Fig. 14: Lung of experimentally infected chicks showing congestion of blood vessels with perivascular edema and fibrinous exudates inside the alveoli. H\&E. X 100

Fig. 15: Heart of experimentally infected chicks showing edema leucocytic infiltration among hyaline degeneration of cardiac muscle fiber. H\&E. X 300

Fig. 16: Liver of experimentally infected chicks showing vacuolar degeneration and necrosis of the hepatic cells with congestion of blood vessels. H\&E. X 300

\section{DISCUSSION}

Ascites syndrome in broilers is an often-fatal cascade of events that result in cardiac anomalies including an enlarged, flaccid heart, and right ventricular hypertrophy, as well as an accumulation of fluid in the abdominal cavity (Janice 2003).

Clinically affected broilers were smaller than normal, listless with ruffled feathers and pale shrunken comb. Severely affected birds have abdominal distension increase respiratory rate. The postmortem lesions were severe marked venous congestion carcasses with deep red colour of the carcasses musculature. The heart showed cardiac enlargement including dilation of the right atrium and the right ventricle 
and hypertrophy of both the right ventricle and right muscular atrioventricular valve. Hydropericardium also present. Similar clinical signs and postmortem findings of ascitic chickens were reported by Tafi and Karima, (2000); Saif et al. (2003) and Olkowski et al. (2007).

The heart and lungs do not harbor bacteria as a part of the normal flora of broilers (Tankson et al., 2002a). In fact, attempts to isolate bacteria from the heart and lungs of apparently healthy chicks have not been reported. But when chicks are stressed, bacteria often penetrate protective barriers of the respiratory tract and inflict damage to the heart and lungs (Tanksons et al., 2002 a \& c).

Bacteriological examination of heart, lungs, liver and spleen of naturally affected birds revealed the isolation of Enterococcus spp. E. coli, Klebsiella pneumoniae, Pseudomonas aeruginosa, Citrobacter and Staphylococcus (51.11 and 53.84\%), (22.22\% and 23.07\%), (2.22\% and $3.84 \%),(2.22 \%$ and $0.0 \%),(6.66 \%$ and $5.76 \%)$ and $(4.44 \%$ and $3.84 \%$ ) from diseased and freshly dead ascitic birds. This result nearly coincided with that of (Tankson, 2001) and (Tankson et al. 2002a). In addition, Janice, (2003) reported that all ascitic birds were victims of bacterial or viral infection.

Tottori et al.( 1997) and Saif et al. (2003) reported that Increased resistance to blood flow through the lung due to lung damage as a consequence of infectious agents can cause pulmonary hypertension and, consequently, right ventricular failure and ascites developed. Simply, when the lungs cannot meet the demand for oxygen it sends a signal to the brain to increase blood flow. The heart then begins to beat faster and increases blood flow. The right ventricle is undersized and the heart cannot handle the returned backpressure. This backpressure causes an over pressure in the liver, which in turn starts to seep plasma into the body cavity (Water Belly) Therefore, either the liver shuts down or the heart developed anomalies causing death. (Janice, 2003).

Concerning, the result of Enterococcus identification, pure cultures of Enterococcus colonies on blood agar varied from pinpoint from $0.5 \mathrm{~mm}$ to $1.0 \mathrm{~mm}$ in diameter. They were grey transparent to white and surrounded by a more or less pronounced zone of haemolysis. They were Gram positive, catalase negative cocci and tolerate growth on $\mathrm{NaCl} 6.5 \%$. They were identified based on their biochemical properties as Enterococcus faecalis, Enterococcus durans and Enteococcus hirae, similar colonial morphology and biochemical characters were reported for Enterococci identification by (Murray, 1990), (Linda and Paul 1992) and (Quinn et al. 1994 \& 2002). 
Although, different species of bacteria were isolated and identified from heart, lungs of ascitic chicks. None of the isolated bacteria was found to be resident in any organs. However, Enterococcus faecalis notably was found at rate of (35/75) $46.66 \%$ from all examined samples .This observation was completely agreed with (Tankson et al. 2002a) they reported that, different bacteria species were isolated from the heart and lungs of chickens. Only one bacterium Enterococcus faecalis, was isolated at every sampling and more time than other bacteria. In the same context Enterococcus faecalis constitute $68.62 \%$ (35/51) from the isolated Enterococcus spp. Followed by Enterococcus durans and Enterococcus hirae which were isolated at rate of $19.60 \%$ $(10 / 35)$ and $11.76 \%(6 / 51)$ respectively. This result was supported by Sebastian (2007) who declared that enterococcus spp are inhabitant of intestinal tract of human, animals and chickens. Approximately 85-90\% of the enterococcal infections are attributed to Enterococcus faecalis, which was previously refered as Streptococcus faecalis. When it inadvertently enters circulation, it can cause endocarditis. Also Smyth and McNamee, (2001) reported that the most common enterococcus spp causing septicaemia and localized infection in poultry are Enterococcus faecalis, Eenterococcus durans and Enteococcus hirae .

Chadfield et al. (2005) reported that infections with E. hirae appear to include young chickens with majority of septicemia and endocarditis affection in the right side of the heart. Attention has focused on enterococci not only because their increasing role in infection, but also of their remarkable and increasing resistance to antimicrobial agents (Murray, 1990 and Tejedor et al. 2005).

Our results revealed that Enterococcus spp. were found to be highly sensitive to amoxicillin and sensitive to enrofloxacin and ciprofloxacin while they were resistance to Aminoglycoside (gentamycin and streptomycin), tetracycline and Chloramphenicol. (Lukaasova and Sustackova, 2003; Urumova et al., 2005; and Paulo et al., 2007) recorded similar observation. Bogaard et al. (2002) found that Enterococcus spp isolated from poultry were highly resistance to most antibiotic used including aminoglycosides and susceptible to amoxicillin and ciprofloxacin

Regarding, the experimental study, the inoculated birds showed increase respiratory rate, reduce exercise tolerance and ruffled feather from 4 to 7 days post infection. Some showed distended abdomen with pale head 11 days post infection. 
While post mortem lesion showed septicemia including general hyperemia, hepatomegaly, spleenomegaly perihepatitis, pericarditis. Some birds showed straw yellow fluid occupying the abdominal cavity, liver was congested and showed dark red discoloration and some birds developed hydro-pericardium, similar clinical signs and postmortem lesion were recorded in experimental infection induced by Tankson et al. (2001 \& 2002 c); Yamaguchi et al. 2000 and Chadfield et al., 2005

The incidence of ascites development was 60\%, 40\%, 50\% and $20 \%$ for Enterococcus faecalis, Enterococcus durans, Enterococcus hirae and E. coli respectively. Tankson et al. (2002 c) reported similar results where, they induced $70 \%$ ascites in chickens inoculated with Enterococcus faecalis. Also, Yamaguchi et al (2000) reported that ascites was produced in $14 \%$ of broilers inoculated with E. coli (0111) intratracheally.

No doubt that pulmonary hypertension syndrome plays a significant role in the pathogenesis of ascites in broiler chickens (Olkowski et al., 1998). An early sign of PHS in chickens is a cavity or depression on the external surface of the right ventricular wall, similar to that caused by hypoxia (Julian, 1988 and Hoerr, 1988).

The results also showed that hearts of experimentally infected birds developed visible cavity formation in the wall of right ventricle especially in Enterococcus inoculated groups with high incidence in $E$. faecalis $(60 \%)$. A heart scoring system was based upon this visible external cavity on the RVW which completely agreed with heart scoring system observed by (Tankson et al., 2001). Who showed that this depression occurred on the external surface of the RVW of $95 \%$ of chickens administered E. faecalis, at dose of $2 \times 10^{7}$ organisms either intra-abdominally or by the intravenous routes. In the same context, PHS results when blood pressure in the pulmonary tree increases (Julian, 1988 and Hoerr, 1988). Backpressure causes the right ventricle of the heart to become overworked. This leads to right ventricular hypertrophy and thinning of the RVW (Julian, 1988). The visual manifestation of this damage to the RVW in chickens is a cavity on the external surface of the right side of the heart. However, the cavity in the RVW develops before accumulation of ascites fluid in the abdominal cavity. Thus, the scoring system was able to differentiate birds challenged from non-challenged controls.

No bird was found to be suffering from both ascites and pericarditis especially in E. coli infected group. It can be suggested that experimental E. coli inoculation into the trachea of these broilers can be 
divided into two disease patterns. In the first, the body weight decreased because of development of E. coli septicemia, with some deaths. In these cases, the birds did not develop ascites. In the second pattern, the birds continued growing during and after respiratory problems, and some birds developed ascites, enlargement of the RV, or mild pericarditis. This may be attributed to the lack of oxygen caused by the lung lesion and that the $\mathrm{RV}$ is enlarged because of its work overload pumping sticky blood through the capillary bed of the lung. Such suggestion is completely agreed with Yamaguchi et al. (2000).

All infected and treated birds developed neither clinical signs nor mortalities, this may be attributed to the potent action of susceptible antibiotic used which hinder the effect of the inoculated bacteria and prove that bacteria have a considerable role in development ascites syndrome in comparison to infected non-treated groups.

All control birds used for experimental study were negative by culture for the challenge strains used in the study and no clinical signs or gross lesions were demonstrated in these birds.

Concerning histopathological study, there were no great difference between naturally infected birds with ascites and experimentally induced ascites birds. The main cardiac histological lesions were epicardial fibrosis, hyaline degeneration of myocardial muscles and destruction of cardiac muscle fiber with leucocytic infiltration and edema among the cardiac muscle .Hepatic changes were thickening of the fibrous tissue of the hepatic capsule, vacuolar degeneration and necrosis of the hepatic cells together with severe congestion and dilation of the hepatic sinusoid. While spleen showed congestion and dilation of the splenic blood vessels with hyperplasia of the endothelial lining Bl.Vs. depletion of lymphocytes of the white bulb and thickening of the splenic capsule was observed.

Lung showed serofibrinous exudates inside the alveoli and congestion of the blood vessels, desquamation of the epithelial cells of the bronchioles in addition to collapse and compensatory emphysema. Similar findings were reported by Nakamura et al. (1999) Cardiac histologic lesions of ascitic birds, included myocardial degeneration with and pericardial fibrosis while the liver showed ,hepatic degeneration, necrosis and hepatic capsule fibrosis. Also Tafi and Karima, (2000) found that the histopathological changes in naturally affected chickens by ascites syndrome were congestion, dilatation of parabronchi and adjacent air capillaries, hypertrophy of smooth muscle of parabronchial walls of lung. Congestion, oedema and myofiber 
degeneration of heart, pronounced dilatation of sinusoids, atrophy and degeneration of hepatocytes, marked thickening of capsule, congestion, disappearance of white bulb and mild to severe thickening of capsule in the spleen. Tottori et al. (1997) and Yamaguchi et al. (2000) found that in an experimentally induced ascites in chickens, the main lesions in lung were moderate hyperplasia of the bronchial epithelium, lymphocytic infiltration of the mucosal lamina propria,. Minimal inflammatory cell infiltration was found in the liver capsule and between the myofibrous tissue in the heart, accompanied with edema in the interstitial tissue and congestion, sometimes with hemorrhages.

Finally, ascites syndrome in broilers is an often-fatal cascade of events that results in cardiac anomalies including an enlarged heart, and right ventricular hypertrophy, as well as an accumulation of fluid in the abdominal cavity. No doubt that respiratory diseases and consequently lung damage caused by infectious agents' leads to hypoxemia and tissue hypoxias that are very prominent features in ascites.

Different bacterial agents were isolated from ascitic birds specially Enterococcus faecalis, enterococcus durans, Enterococcus hirae and E. coli with variable percentage and they were able to induced ascites in experimentally infected chicks besides many cardiac anomalies. So, our results clearly refutes the postulation of completely exclusion of infectious agents as an etiology of ascites development in broilers.

\section{REFERENCES}

Bancroft, J.D.; Stevens, A. and Turner, D.r. (1990): Theory and practice of histological technique. 3rd Ed, churchil, living stone Edinburgh, London, Melbourne \& New Yourk.

Bogaard, E.; Willems, R.; London, N.; Top, J. and Stobberingh, E. (2002): Antibiotic resistance of faecal Enterococci in poultry, poultry farmers and poultry slaughterers. Journal of Antimicrobial Chemotherapy 49, 497-505

Chadfield, M.S.; Bojesen, A.M.; Christensen, J.P.; Juul-Hansen, J.; Saxmose Nielsen, S. and Bisgaard, M. (2005): Reproduction of sepsis and endocarditis by experimental infection of chickens with Streptococcus gallinaceus and Enterococcus hirae. Avian Pathology 34 (3), 238/247

Druryan, S.; David, A. and Cahanr, A. (2007): Development of ascites resistance and ascites susceptible broiler line. Poultry science (86) 811-822. 
Edwards, P.R. and Ewing, W.H. (1972): Identification of Enterobacter aerogenesiaceae, Burgess publ. co. Minnecopolis Minnesota. P. 103

Hoerr, F.J. (1988): Pathogenesis of ascites. Poultry Digest 46:8-12.

Janice, M.B. (2003): Ascites Syndrome (Pulmonary Hypertension Syndrome) in Broiler Chickens: Are We Seeing the Light at the End of the Tunnel? Avian and Poultry Biology Review (3), (99-126)

Julian, R.J. (1988): Pulmonary hypertension as a cause of right ventricular failure and ascites in broilers. Zootechnia Int. 11:58

Julian, R.J. (1993): Ascites in poultry. Avian Pathol 22: 419-454.

Julian, R.J. (1998): Rapid growth problems: ascites and skeletal deformities in broilers. Poult. Sci. 77:1773-1780.

Linda, M.K. and Paul, A.H. (1992): Routine Procedures for Isolation and Identification of Enterococci and FecalStreptococci. Applied and Environmental Microbiology, P.3027-3031

Lukaasova, J. and Sustackova, A. (2003): Review Article: Enterococci and Antibiotic Resistance. ACTA VET. BRNO, 72: 315-323

Maxwell, M.H. and Robertson, G.W. (1997): World broiler ascites survey. Poultry international 36: 16-30.

Murray, B.E. (1990): The life and times of the Enterococcus. Clin Microbiol Rev 3: 46-65.

Nakamura, K.; Yoshihiro, B.; Zenato, M. and Tomoyuki, S.H. (1999): Comparative Pathology of Heart and Liver Lesions of Broiler Chickens That Died of Ascites, Heart Failure, and others. Avian Diseases 43: 526

NCCLS. (2002): Performance Standards for Antimicrobial Disk and Dilution Susceptibility Tests for Bacteria Isolated from Animals; Approved Standard, Second Edition. NCCLS document M31-A2 (ISBN 1-56238-461-9). NCCLS, 940 West Valley Road, Suite 1400, Wayne, Pennsylvania 19087-1898, USA.

Olkowski, A.A.; Classen, H.L. and Kumor, L. (1998): Left atrioventricular valve degeneration, left ventricular dilation and right ventricular failure: a possible association with pulmonary hypertension and aetiology of ascites in broiler chickens. Avian Pathology, 27, 51-59.

Olkowski, A.A.; Nain, S.; Wojnarowicz, C.; Laarveld, B.; Alcorn, J. and Ling, B.B. (2007): Comparative study of myocardial high energy phosphate substrate content in slow and fast growing 
chicken and in chickens with heart failure and ascites. Comparative Biochemistry and Physiology, Part A (148) 230238.

Paulo, M.; Manuela, O.; Alexandra, B.; Paulo Vaz-Pires and Fernando, B. (2007): Antimicrobial resistance in Enterococcus spp. and Escherichia coli isolated from poultry feed and feed ingredients. Veterinary Microbiology (120) 122-131.

Quinn, P.J.; Carter, M.E.; Markery, B.K. and Carter, G.R. (1994):

Clinical Veterinary Microbiology. Year book, Wolf publishing. Europ limited.

Quinn, P.J.; Markery, B.K.; Carter, M.E.; Donnelly, W.J. and Leonard, F.C. (2002): Veterinary Microbiology and Microbial Diseases. Blackwell Science Ltd. 1st Published.

Saif, Y.M. and Fadly, A.M. Beard., H.G. and MDougald, L.R. (2003): Diseases of poultry $11^{\text {th }}$ eds. Ames.Iowa State University press

Sebastian, G.B. (2007): Enterococci and streptococci . International Journal of Antimicrobial Agents 29 Suppl. 3- S43-S52

Smyth, J.A. and McNamee, P.T. (2001): Staphylococci, Streptococci and Enterococci. In F. Jordan, M. Pattison, D. Alexander \& T. Faragher (Eds.), Poultry Diseases, 5th ed. (pp. 163 /169). London: W.B. Saunders

Tafi, A.K. and Karima, M.R. (2000): Morphological studies on natural ascites syndrome in broiler chickens. Veterinarski Arhiv 70 (5), 239-250.

Tankson, J.D. (2001): Enterococcus faecalis and pulmonary hypertension syndrome in chickens. Ph.D in animal physiology.dept. of poultry science .Mississippi State University, Mississppi- USA

Tankson, J.D., Thaxton, J.P., and Vizzier-Thaxton, Y. (2001): Pulmonary hypertension syndrome in broilers challenged with Enterococcus faecalis. Infect Immun 69:6318-6322, 2001.

Tankson, J.D.; Thaxton, J.P. and Vizzier-Thaxton, Y. (2002a): Bacteria in heart and lungs of young chicks. Journal of Applied Microbiology, 92, 443-450

Tankson, J.D.; Thaxton, J.P. and Vizzier-Thaxton, Y. (2002b): Morphological Changes in Heart and Lungs of Broilers Experiencing Pulmonary Hypertension Syndrome Caused by Enterococcus faecalis. Poultry Science 81: 365-370.

Tankson, J.D.; Thaxton, J.P. and Vizzier-Thaxton, Y. (2002c): Pulmonary Hypertension Syndrome in Young Chickens 
Challenged With Frozen and Autoclaves Cultures of Enterococcus faecalis. Experimental Biology and Medicine 227: 812-816

Tejedor, M.T.O.; Afonso, R.J.L.; Barrasa, M. and Gonzalez, M. (2005): Antimicrobial susceptibility of Enterococcus strains isolated from poultry faeces. Research in Veterinary Science, Volume 78, Issue 1, Pages 33-38

Tottori, J.; Yamaguchi, R.; Murakawa, Y.; Sato, M.; Uchida, K. and Tateyama, S. (1997): Experimental production of ascites in broiler chickens using infectious bronchitis virus and Escherichia coli. Avian Dis. 41: 214-220. 1997.

Urumova, V.; Lyutzkanov, M. and Petrov, V. (2005): in vitro study of antimicrobial sensitivity of enterococcus isolates from farm birds. Trakia Journal of Sciences, Vol. 3, No. 5, pp 40-45.

Yamaguchi, R.; Tottori, J.; Uchida, K.; Tateyama, S. and Sugano, S. (2000): Importance of Escherichia coli Infection in Ascites in Broiler Chickens Shown by Experimental Production Avian Diseases, Vol. 44, No. 3. pp. 545-548. 
Assiut Vet. Med. J. Vol. 54 No. 117 April 2008

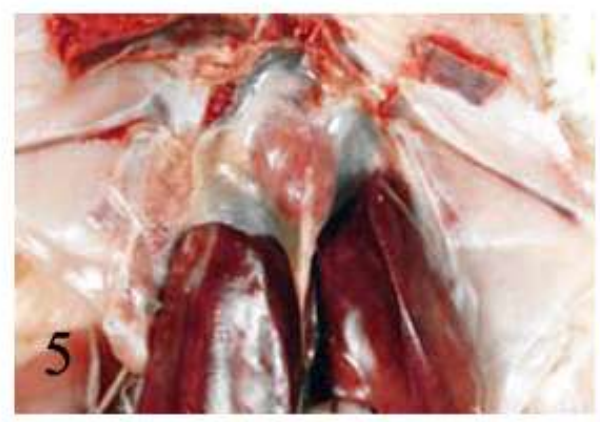

6
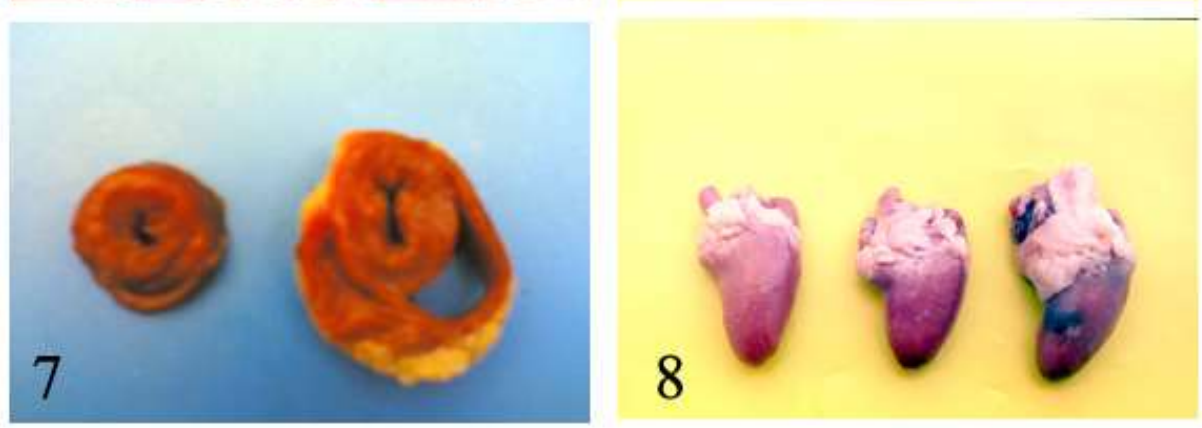

ron 
Assiut Vet. Med. J. Vol. 54 No. 117 April 2008
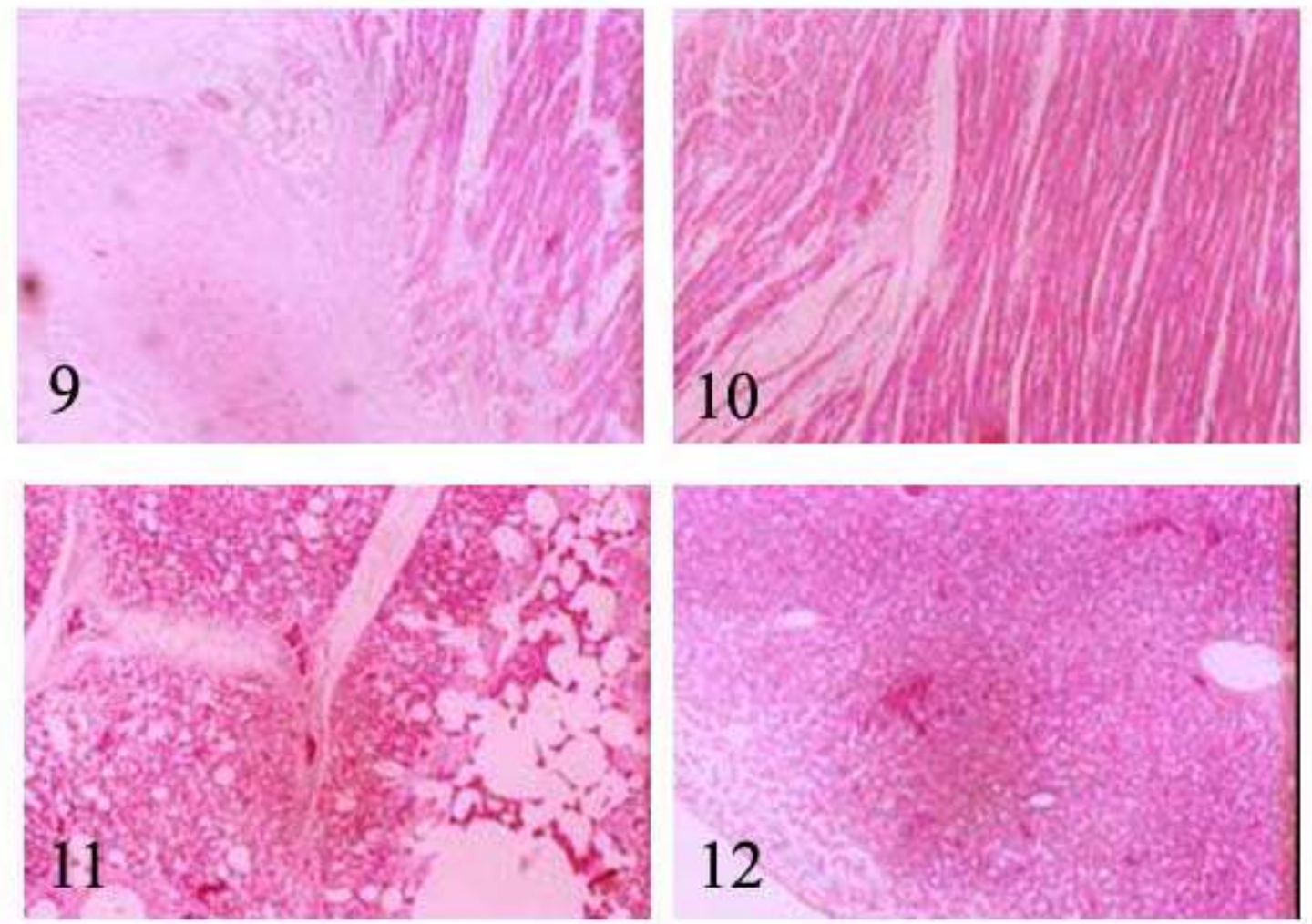
Assiut Vet. Med. J. Vol. 54 No. 117 April 2008
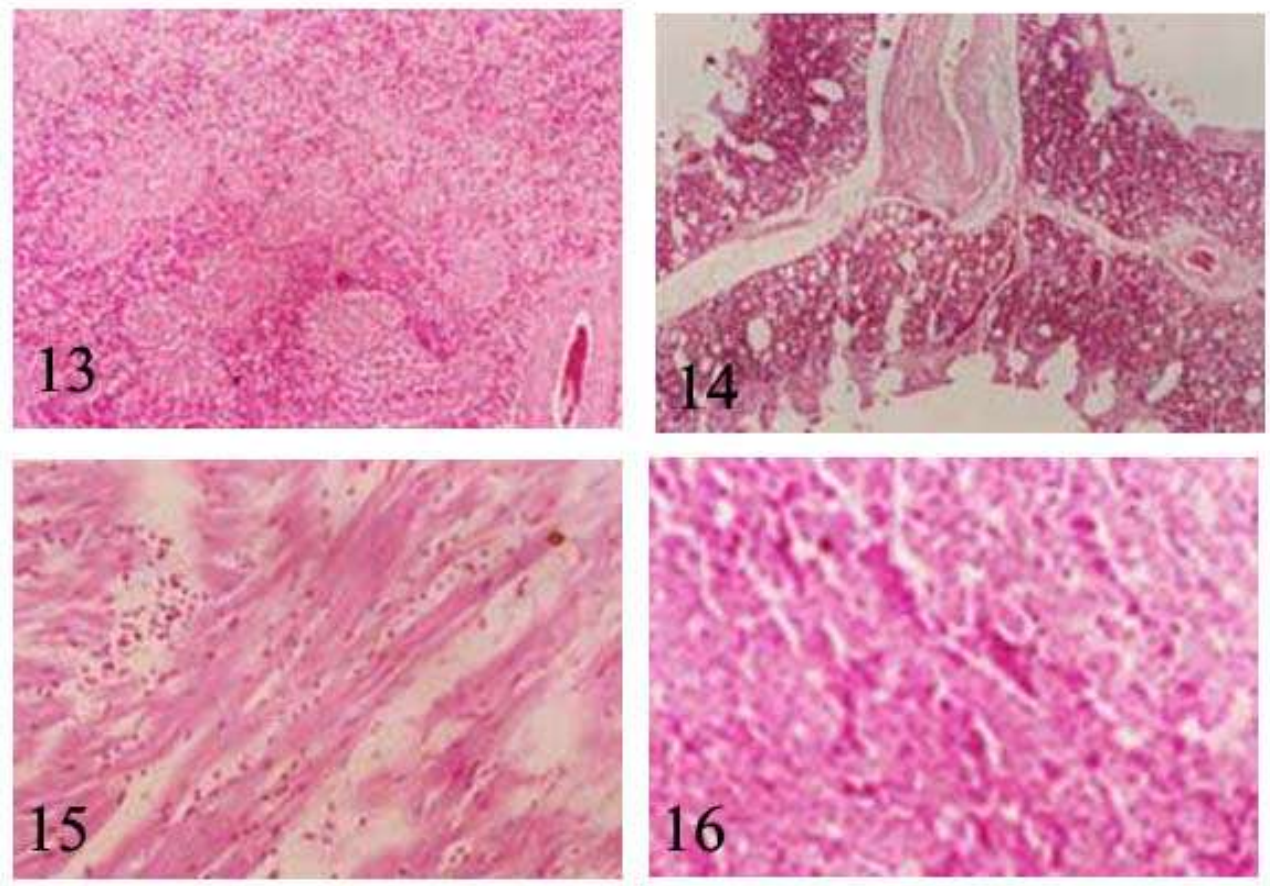